\title{
Subcritical Water Extraction of Phenolic Compounds from Moringa Oleifera Leaf
}

\author{
Siti Zullaikah ${ }^{1}$, Irfan Saputra ${ }^{1}$, Ghuzrina Prihandini ${ }^{1}$, and M. Rachimoellah ${ }^{1}$
}

\begin{abstract}
Moringa oleifera leaf is a good source of phenolic compounds that are reported to exhibit antioxidant activity both in vitro and in vivo. This study investigated the extraction of phenolic compounds from Moringa oleifera leaf using subcritical water. Experiments were performed in a batch stainless steel reactor at temperature ranging from 100 to $3000 \mathrm{C}$ at residence time of 5 to $20 \mathrm{~min}$. Subcritical water extraction resulted the highest yield of product, total phenolic compounds and antioxidant activity at temperature of $200 \mathrm{oC}$ at residence time of 15 minutes. The yield of product, total phenolic compounds and antioxidant activity obtained were $30.661 \%, 48.733 \mathrm{mg}$ tannat acids/ g dry powder of extract and $45.863 \mathrm{mg}$ ascorbic acid/L, respectively. Subcritical water at $200^{\circ} \mathrm{C}$ and $15 \mathrm{~min}$ might be a good substitute to organic solvents such as ethanol to obtain phenolic compounds from Moringa oleifera leaf.
\end{abstract}

Keywords — antioxidant, hydrothermal, Moringa oleifera leaf, phenolic, subcritical water.

\section{INTRODUCTION}

A ntioxidant plays an important role in life. Natural antioksidant has more benefits, such as no toxic and more easily degradable by bodies than artificial antioksidant. Moringa oleifera leaf rich with natural antioksidant, it has many constituents such as phenolic, flavonoid, proanthocyanidin, vitamin $C$, vitamin $E, \beta$ carotene, zinc and selenium where it has very potent to antioxidant activities [1-2]. Every constituent has part in the plant, so flavonoids and phenolics has occasionally huge constituent. Function of flavonoid as pigment gives color of flower, fruit and leave which another one of flavonoid is anthocyanin [3]. Flavonoid can purpose as antioxidant in human body such as Quercetin, Scuttilarein, Galloyl quercitrin and Glucopyranoside [4]. As we known, phenolic is another one of antioxidant constituent where it has high solubility in water and fat [5].

Moringa oleifera lam (Family: Moringaceae) is commonly known as drumstick tree or horse radish tree. The leaf are highly nutritions, being a significant source of $\beta$-carotene, vitamin $C$, protein, iron and potassium. Leaf can be eaten fresh, cooked, or stored as dried powder for many months without refrigeration, and reported almost without loss of nutritional value. Almost all of the parts of the plants have been used for various elements in the indigenous medicine of South Asia, including the treatment of inflammation and infectious diseases along with cardiovascular, gastrointestinal, hematological and hepatorenal disorders [6-7]. Leaves of Moringa oleifera have been reported to regulate thyroid status and possess radioprotective [8] and antitumor [9] activities. Pod showed hypotensive [10] and chemomodulatory effects [11] whereas seeds have been reported for coagulative, antimicrobial and antitumor activity [12]. Roots possessed antimicrobial and antiinflammatory activities [13]. Extracts from Moringa oleifera roots and flowers were found to have a significant hepatoprotective effect [14]. Moringa oleifera contains various phytochemicals, viz carotenoids,

Siti Zullaikah, Irfan Saputra, Ghuzrina Prihandini, and M. Rachimoellah are with Departement of Chemical Engineering, Faculty of Industrial Technology, Institut Teknologi Sepuluh Nopember, Surabaya, 60111, Indonesia. E-mail: szulle@chem-eng.its.ac.id. vitamins, minerals, amino acids, sterols, glycosides, alkaloids, flavonoids and phenolics [5][4].

Finding green alternative extraction is very important and is becoming one of the main topics recently. Subcritical water extraction (SWE) has become an increasing alternative technology in the preparation of environmental sample, and extraction of natural products from herbal plants and foodstuffs [15-16]. Water is environmentally friendly solvent to extract phenolic compounds, it has very strong hydrogen bonding, but the hydrogen bonds break down at temperatures above the superheated. At this method, water is used at temperature below the critical value of water $(3740 \mathrm{o})$ but above $100 \mathrm{oC}$ and at pressure that is sufficiently high ( $>40 \mathrm{bar}$ ) to maintain the liquid state [17]. The extraction typically takes 5 to 30 minutes when using only milli-Q distilled water as the solvent [18].

Before Subcritical Water Extraction technology, extraction of Moringa oleifera leaf has used conventional methode, such as squezzing extraction, decoction, meceration, percolation and soxhlet extraction. The extraction method of Moringa oleifera leaf based on yield in which maceration got the best. Maceration with $70 \%$ ethanol, for 72 hours, is the most suitable extraction method of the dried leaf of Moringa oleifera. It promoted high yield of the crude extract, the highest contents of total phenolics, total flavonoid, major activity compounds and the most potent antioxidant activity [19]. As we known, conventional extraction methods have several drawbacks; e.g. they are time-consuming, low of selectivity, give low extraction yield and use large amount of expensive, explosive and sometimes toxic organic solvents [20]. Solubility of phenolic compounds in common organic solvent is low, so Moringa oleifera leaf are treated at high temperature and/or under acidic and basic conditions [21].

In facts, its applications are due to the manipulation of its dielectric constant, and variable concentration of hydrogen hydroxide with temperature. For instance, its dielectric constant decreases from 80 (at room temperature) to 27 (at $250 \mathrm{oC}$ ) almost equaling of ethanol at ambient temperature [22]. The increase/decrease in hydrogen is a hydroxide ions in subcritical water [23] along with decreasing of its dielectric constant, make it very suitable medium for the extraction and hydrolysis of natural matrices. In other word, Subcritical water 
extraction technology is suitable alternative for antioksidant production from a technical and environmental point of view.

\section{MATERIAL AND METHOD}

\section{A. Materials}

Folin-Ciocalteu reagent, sodium bicarbonate (Na2CO3) and methanol were purchased from Merck. Ethanol, Methanol, Natrium carbonate and ascorbic acid are purchased from Brataco, Surabaya, and supplier of chemical compounds. Tannat acid and 1,1-diphenyl-2picrilhydrazyl (DPPH) purchased from WAKO, Japan.

\section{B. Plant Materials}

The dried powdered leaf were provided to particular ratio (1 grams: $6 \mathrm{~cm} 3$ ). The extract was filtered and the marc was re-extracted by the same process and solvent until the extraction was exhausted [24].

\section{Hydrothermal Extraction}

A batch reactor used for subcritical water treatment was stainless steel tube (SUS316, i.d. $16.5 \mathrm{~mm} \times 150.4$ $\mathrm{mm})$ with a Swagelok fitting. In typical experiment, an accurately weighed amount of dried leaves of Moringa oleifera (about 3 grams) and about $18.0 \mathrm{~cm} 3$ of water were charged into reactor. The reactor was heated in furnace dependent on temperature (100, 150,200,250 and $300 \mathrm{oC})$ and time (5, 10, 15, and 20 minutes). Increasing temperature of reactor was followed with increasing pressure which was depended of ratio [34].

\section{Determine of Total Phenolic Compounds Content}

The content of total phenolic compounds was determined using Folin-Ciocalteu procedure [25]. Each sample $(1 \mathrm{mg} / \mathrm{mL}), 0,1 \mathrm{~mL}$ was mixed with $0,5 \mathrm{~mL}$ of the Folin-Ciocalteu reagent and $2 \mathrm{~mL}$ of sodium bicarbonate solution $(7.5 \%$ w/v). The mixture was allowed to stand at room temperature for 60 minutes with intermittent shaking. The absorbance was measured at $779 \mathrm{~nm}$ using a UV-Visible (UV-VIS) Spechtrophotometer (Pothitirat et al., 2009). Total phenolic compounds was expressed as mg of Tanat acid equivalents in $1 \mathrm{~g}$ of the exract and dried powder, using the following equation based on the calibrattion curve: $\mathrm{Y}$ $=378,09 x, \mathrm{R} 2=0,9796$. Where $\mathrm{x}$ is the absorbance and $\mathrm{Y}$ is the Tannat acid equivalent ( $\mathrm{mg} / \mathrm{g}$ ).

\section{E. Determination of Antioksidant Activity}

The free radical scavenging activity of the extracts and of standard solutions (Tanat acid and quercetin) were investigated using 1,1-diphenyl-2-picrilhydrazyl (DPPH) radical scavenging method [25]. A total of $2 \mathrm{~mL}$ of the extract or standard (vitamin C) was added to $2 \mathrm{~mL}$ of DPPH in methanol solution. The mixture was allowed to stand at room temperature for 30 minutes with intermittent shaking. The absorbance of each solution was determined at $517 \mathrm{~nm}$ using UV-VIS Spechtrophotometer (Pothitirat et al., 2009). Antioxidant activity was expressed as mg of vitamin $C$ equivalents in $1 \mathrm{~L}$ of the solution, using the following equation based on the calibration curve: $\mathrm{Y}=244,6 \mathrm{x}, \mathrm{R} 2=0,9358$. Where $\mathrm{x}$ is the absorbance and $\mathrm{Y}$ is the vitamin $\mathrm{C}$ equivalent $(\mathrm{mg} / \mathrm{g})$.

\section{RESULT AND DISCUSSION}

A. Effect of Time and Temperature on Yields, Total Phenolic Compounds and Antioxidant Activities at Subcritical Water Extraction.

Under subcritical conditions, the intermolecular hydrogen bonds of water break down and the dielectric constant of water decreases. The dielectric constant of ethanol and of pure water at ambient temperature and pressure are 27 and 79, respectively. As temperature increases to $250^{\circ} \mathrm{C}$, the water dielectric constant is reduced to 27 , which is similar to the dielectric constant of ethanol [26]. The subcritical water extraction was evaluated by the extraction yield (\%) of crude extract. That process provided the highest yield of $30,661 \%$ at temperature of $200 \mathrm{oC}$ and time of 15 minutes. Figure 1 shown sharply effect of temperature and time on yield (\%).

The effect of water temperatures in the range of 100 $300 \mathrm{oC}$ on the efficiency of subcritical water extraction was investigated. The extraction rate of yield increased as the extraction temperature increased to $200 \mathrm{oC}$, and then the extracted quercetin was gradually degraded as the temperature increased above 200oC. These results were similar to another author [27] although the extraction rate increases with temperature, some desired organics show substantial degradation at temperatures $>150 \mathrm{oC}$ with subcritical water extraction that higher temperatures may lead to degradation and loss of desirable compounds because of thermal instability. These results indicate that the efficiency of subcritical water extraction is greatly affected by the extraction temperature. A higher temperature increases the solubility of phenolic compounds (Figure 2). Moreover, the temperature at which the highest amount of phenolic compounds (48.733 $\pm 0.01 \mathrm{mg}$ Tannat acid/g of extracts of dried powder) was extracted (200oC) affects. The obtained results indicate that temperatures between 200 $250 \mathrm{oC}$ are the most suitable for subcritical water extraction of phenolic compounds from Moringa oleifera leaf. Obviously, the production of phenolic compounds was also a function of residence time. Both yield, total phenolic compounds and antioxidant activity showed peak at around $15 \mathrm{~min}$, and then decreased at around 20 minutes. After $15 \mathrm{~min}$, produced total phenolic compounds may be decomposed by subcritical water.

Generally, phenolic compounds have antioxidant activity; however, it was probable that besides phenolic compounds, other nonphenolic compounds with antioxidant activity were also produced and/or extracted from Moringa oleifera leaf in subcritical water medium. Therefore, antioxidant activity as a criterion of total produced antioxidants was also investigated. Fig. 3 shown effect of temperature and time at the antioxidant activity.

Generally, phenolic compounds have antioxidant activity; however, it was probable that besides phenolic compounds, other nonphenolic compounds with antioxidant activity were also produced and/or extracted from Moringa oleifera leaf in subcritical water medium. Therefore, antioxidant activity as a criterion of total produced antioxidants was also investigated. Fig. 3 shown effect of temperature and time at the antioxidant activity. 


\section{CONCLUSION}

Decomposition and conversion of Moringa oleifera leaf into valuable chemical compounds were successfully conducted using subcritical water. Degradation of the phenolics complexes of Moringa oleifera leaf were achieved (up to $30.65 \%$ of Moringa oleifera leaf) in the water without using organic solvent, acid, base, and/or enzyme. Decomposition of Moringa oleifera leaf have resulted almost the same amount of phenolic compounds; it was understood that phenolic compounds were mainly produced. Some of phenolic compounds and antioxidant activities were identified and quantified in this study.

Subcritical water extraction resulted the highest yield of product, total phenolic compounds and antioxidant activity at temperature of $200 \mathrm{oC}$ at residence time of 15 minutes. The yield of product, total phenolic compounds and antioxidant activity obtained were $30.661 \%$, 48.733 mg tannat acids/ g dry powder of extract and $45.863 \mathrm{mg}$ ascorbic acid/L, respectively. Subcritical water temperature and residence time were two studied parameters which influenced the decomposition of Moringa oleifera leaf and production of phenolic compounds. It was found that phenolic compounds could be selectively produced by temperature variations. From residence time point of view, production of phenolic compounds could be efficiently achieved in a very short time which was much less than those reported in conventional methods that increases economic feasibility of this method.

\section{ACKNOWLEDGEMENT}

The authors are grateful to Dr. Rer. Nat Fredy Kurniawan, M.Si, head of Instrumentation and Science Analytical Laboratorium, Chemistry, Natural of Science, Institute Technology of Sepuluh Nopember. Any opinion expressed and conclusions arrived at, are those of the authors and not necessary to be attributed to Institute Technology of Sepuluh Nopember.

\section{REFERENCES}

[1]. Aqil, F., Ahmad, I., \& Mehmood, Z. 2006. Antioxidant and free radical scavenging properties of twelve tradisional used Indian medicinal plants. In: Moyo, B., Oyedemi, S. Polyphenolic content and antioxidant properties of Moringa oleifera leaf extracts and enzymatic activity of liver from goats supplemented with Moringa oleifera leaves/sunflower seed cake. Turkish journal of Biology, 30, 177-183.

[2]. Okwu, D.E. 2004. Phytochemicals and vitamin content of indigenous spesies of South Eastern Nigeria. Journal of Sustainable Agriculture and Environment, 6, 30-34.

[3]. Zheng, R.L., Huang, Z.Y., 2001. Reactive oxygen spesies. In: Zheng, R.L., Huang, Z.Y. (Eds.), Free Radical and Agricultural Science. China Higher Education Press and Springer Press, Beijing, pp. 17-27.

[4]. Peng, Z.P., Strack, D., Baumert, A., Subramaniam, R., Goh, N.K., Chia, T.F., Tan, S.N., and Chia, L.S. 2003. Antioxidant Flavonoids from leaves of Polygonum hydropiper L. Journal of Phytochemistry In Elsevier Science Ltd,62, 219-228.

[5]. Siddhuraju, P., \& Becker , K.2003. Antioxidant Properties of various solvent extracts of total phenolics constituens from three different agroclimatic origins of drumstick tree (Moringa oleifera lam) leaves. In :Moyo, B., Oyedemi, S. Polyphenolic content and antioxidant properties of Moringa oleifera leaf extracts and enzymatic activity of liver from goats supplemented with Moringa oleifera leaves/sunflower seed cake. Journal of Agricultural and Food Chemistry, 51, 2144-2155.
[6]. Nadkarni, A.K. 1976. Indian Materia Medica. Popular Prakashan, Bombay, pp. 810-816.

[7]. Parrotta, J.A. 2001. Healing Plants of Peninsular India. CABI Publication, pp. 528-530.

[8]. Rao, A.V., Devi, P.U., and Kamath, R. 2001. In vitro radioprotective effect of Moringa oleifera leaves. Indian J. Exp. Biol. 39, 858-863.

[9]. Murakami, A., Kitazono, Y., Jiwajinda, S., Koshimizu, K., Ohigashi, H. 1998. Niaziminin, a thiocarbonate from the leaves of Moringa oleifera, holds a strict structural requirement for inhibition of tumor-promoter-induced Epstein-Barr virus activation. Planta Medicines,64, 319-323.

[10]. Faizi, S., Siddiqui, B.S., Saleem, R., Shahreen, F., Gilani, A.H. 1998. Hypotensive constituents from the pods of Moringa oleifera. Planta Medicine, 64, 225-228.

[11]. Bharli, R.,Tabassum, J., and Azad M.R.H. 2003. Chemomodulatory effect of Moringa oleifera, Lam, on hepatic carcinogen metabolisir enzymes, antioxidant parameters and skin papillomagenesis in mice. Asian Pacific J Cancer Prev, 4, 131-139.

[12]. Guevara, A.P., and Vargas, C. 1999. An antitumor promoter from Moringa oleifera Lam. Mutat. Res. 440, 181-188.

[13]. Ezeamuzle, I.C., Ambadederomo, A.W., Shode, F.O. Ekwebelem, S.C. 1996. Anti-inflammatory effects of Moringa oleifera root extract. International. J. Pharmacogn, 34, 207-212.

[14]. Ruckmani, K., Kavimani, S., Anandan, R., Jaykar, B. 1998. Effect of Moringa oleifera Lam on paracetamol-induced hepatoxicity. Indian J. Pharm. Sci, 60, 33-35.

[15]. Herrero, M., Cifuentes, A., Ibanez, E. 2006. Subcritical and Supercritical fluida extraction of functional ingredients from different natural sources; plants, food-by-products, alga and microalgae. Food Chemicals, 98, 136-148.

[16]. Ramos, L., Kristenson, E.M., Brinkman, U.A.T., 2002. Current used of pressurised liquid extraction and subcritical water extraction in environmental analysis. Journal of Chromatography, A 975, 3-29.

[17]. King, J. 2003. Development and potential of critical fluida Technology in the nutraceutical industry. In: York, P., Kompella, U.B., Shekunov, B.V. (Eds), Drug delivery and Supercritical Fluid Technology. Marcel Dekker, New York, 579614.

[18]. Andersson, T.,2007. Parameters affecting the extraction of Polycyclic aromatik hydrocarbons with pressurised hot water Academic dessertation, University of Helsinki. Finland

[19]. Vongsak, B., Sithisarn, P., Mangmool, S., Thongpraditchote, S. Wongkrajang, Y., and Gritsanapan, W. 2012. Maximizing total phenolics, total flavonoids contents and antioxidant activity of Moringa oleifera leaf extract by the appropriate extraction method. Journal of Crops and Products, xxx, xxx-xxx.

[20]. Wang, L., Weller, C.L. 2006. Recent Advances in extraction of nutraceuticals from plants. Trends Food Science Technology, 17, 300-312,

[21]. Wiboonsirikul, J., Kimura, Y., Kadota, M., Morita, H., Tsuno, T., Adachi, S. 2007. Properties of extracts from defatted rice bran by its subcritical water treatment. Journal of Agricultural in Food Chemicals, 55, 8759-8765.

[22]. Luque de Castro, M.D., Jiminez-Carmona, M.M., Perez, Fernandez., 1999. Towards more rational technique for the isolation of valuable essential oils from plants. Trends Analytica Chemical, 18, 708-716.

[23]. Hatta, S., Wiboonsirikul, J.,Maeda, A., Kimura, Y., Adachi, S.2008. Extraction of defatted rice bran by subcritical water treatment. Biochemical Engineering Jpurnal, 40, 44-53.

[24]. Ko, M.J., Cheigh, C.I., Cho, S.W., Chung, M.S.2010. Subcritical water extraction of flavonol quercetin from onion skin. Journal of Food Engineering, 102, 327-333.

[25]. Pothitirat, W., Chomnawang, M.T., Supabphol, R., Gritsanapan, W., 2009. Comparison of bioactive compound content, free radical scavenging and anti-acne inducing bacteria activities of extract from the mangosteen fruit rind at two stages of maturity. Fitoterapia, 80, 442-447.

[26]. Ramos, L., Kristenson, E. M., \& Brinkman, U. A. (2002) Current use of pressurized liquid extraction and subcritical water extraction in environmental analysis. Journal of Chromatography A, $975,3-29$

[27]. Kubatova, A., Lagadec, A.J.M., Miller, D.J., Hawthorne, S.B. 2001. Selective extraction of oxygenates from savory and peppermint using subcritical water. Flavour and Fragrance Journal 16, 64-73. 


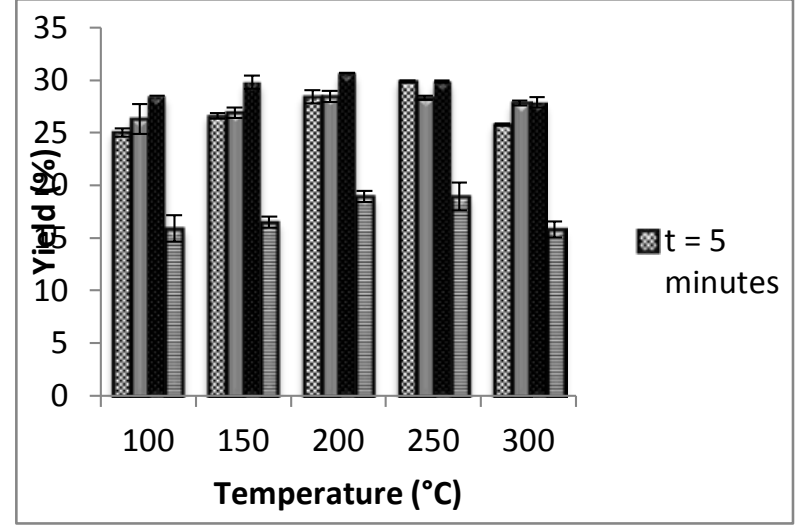

Figure 1. Effect of temperature and time on yield (\%) at subcritical water extraction

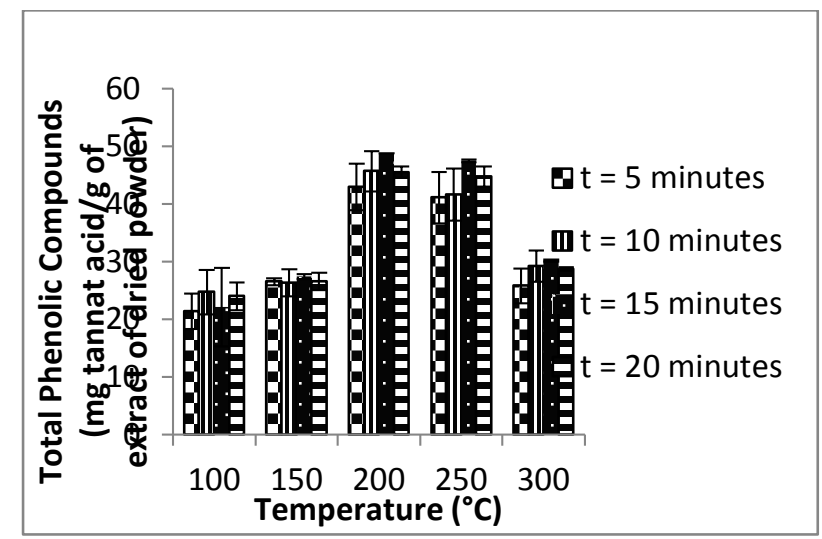

Figure 2. Effect of temperature and time on total phenolic compounds (mg Tannat acid/g extracts of dried powder) at subcritical water extraction

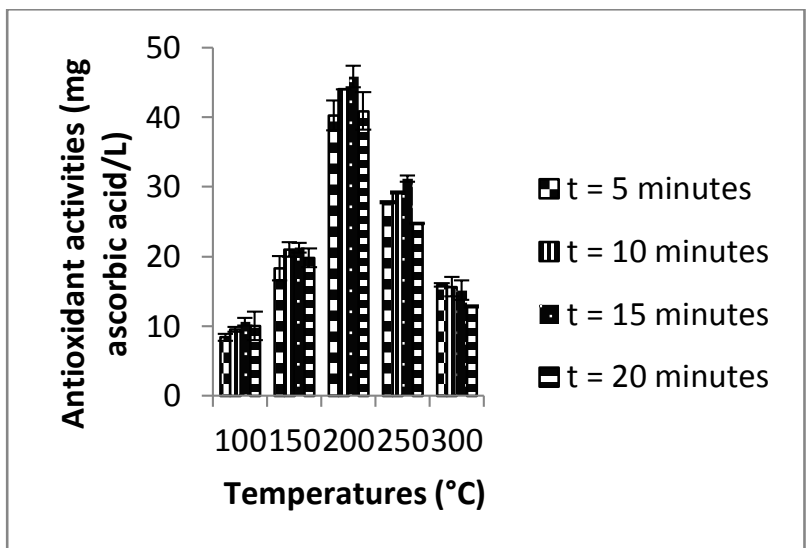

Figure 3. Effect of temperature and time on antioxidant activities (mg ascorbic acid/L) at subcritical water extraction 